\title{
T. DOHI
}

N. KAIO

S. OSAKI

\section{A note on optimal inventory policies taking account of time value}

Revue française d'automatique, d'informatique et de recherche opérationnelle. Recherche opérationnelle, tome 26, n 1 (1992), p. 1-14.

<http://www.numdam.org/item?id=RO_1992_26_1_1_0>

(C) AFCET, 1992, tous droits réservés.

L'accès aux archives de la revue « Revue française d'automatique, d'informatique et de recherche opérationnelle. Recherche opérationnelle » implique l'accord avec les conditions générales d'utilisation (http://www.numdam.org/ legal.php). Toute utilisation commerciale ou impression systématique est constitutive d'une infraction pénale. Toute copie ou impression de ce fichier doit contenir la présente mention de copyright.

\section{Numdam}

Article numérisé dans le cadre du programme

Numérisation de documents anciens mathématiques

http://www.numdam.org/ 


\title{
A NOTE ON OPTIMAL INVENTORY POLICIES TAKING ACCOUNT OF TIME VALUE (*)
}

\author{
by T. Dohi $\left({ }^{1}\right)$, N. Kaio $\left({ }^{2}\right)$ and S. Osaki $\left({ }^{1}\right)$
}

\begin{abstract}
In this paper, we propose the optimal inventory policies taking account of time value by applying the concept of the present value method. In particular, some well-known continuous and deterministic models are analytically and/or numerically discussed taking account of time value. We discuss the inventory systems without and with backlogging allowed. We examine the asymptotic characteristics of the total cost by perturbation of the instantaneous interest rate. We further show numerical examples and describe how to determine the optimal inventory policies. We will affirm that the concept of time value introduced here is useful to accurately evaluate the inventory management policies.
\end{abstract} tion.

Keywords : Deterministic inventory model; instantaneous interest rate; present value; optimiza-

Résumé. - Dans cet article, nous proposons les politiques optimales de gestion de stock tenant compte de la valeur du temps en appliquant le concept de la valeur actuelle. Nous analysons les systèmes avec ou sans commande en attente. Nous examinons les caractéristiques asymptotiques du coût total par perturbation du taux d'intérêt instantané. Nous donnons en outre les exemples numériques et décrivons comment déterminer les politiques optimales. Le concept de valeur du temps introduit ici est utile pour l'évaluation précise des politiques de gestion de stock.

\section{INTRODUCTION}

Many studies about the inventory management system have been reported. In particular, there have been many interesting results in the optimal inventory policies which minimize the cost by using various measures. For example, see Buffa and Sarin [1], Hax and Candea [3], and Tersine [4]. However, so long as we apply cost as the objective function, we should consider the structure of value which has to be evaluated in the system as well as the cost performance. Value is ordinarily separable into intrinsic and time values.

$\left({ }^{*}\right)$ Received September 1990.

( ${ }^{1}$ Dept. of Industrial and Systems Engineering, Hiroshima University, Higashi-Hiroshima 724, Japan.

(2) Dept. of Management Science, Hiroshima Shudo University, Hiroshima 731-31, Japan.

Recherche opérationnelle/Operations Research, 0399-0559/92/01 1 14/\$3.40

(c) AFCET-Gauthier-Villars 
Intrinsic value is based upon economic, productive and other activities. On the other hand, money is endowed with time value by nature and its value ought to reduce as time passes if a great economic change or revolution does not happen. Time value corrections, however, have been seldom applied in the analysis of inventory management.

Generally speaking, although time value corrections for time intervals less than a year are considered to be relatively small, we can not conclude that time value corrections are not needed, since contributions of considering time value to the inventory management depend upon kinds of model, the length of inventory cycle and types of interest rate. Therefore, it is important to investigate how time value influences the various inventory policies. Gurnani [2] discussed the classical inventory models with a finite planning horizon, and examined the difference between inventory models with and without the discount by time value and stated that the discounting by time value causes the optimal order quantity and correspondingly the period length to vary monotonically with the interest rate, and it is not influenced by the inventory system planning horizon.

On the other hand, we can not frequently use the prespecified planning horizon in actual industrial market. Therefore, the total cost over an infinite horizon is often referred in actual inventory management. Trippi and Lewin [6] introduced the present value analysis to the economic order quantity problem with an infinite planning horizon. It should be noted that the discount at the only ordering point is considered in their present value formulation, Further, Thompson [5] showed how the concept of capital budgeting included the present value method can be logically applied to the determination of optimal inventory levels.

In this tutorial paper, we propose the optimal inventory policies for an infinite time span taking account of time value from the different view point from Trippi and Lewin [6]. Namely, we define the inventory holding cost per one cycle as a discounted one in continuous time. Since the holding cost contains a capital cost component and is frequently influenced by time value, it is important to formulate the structure of the holding cost precisely. This treatment for the cost is more realistic and satisfies our intuition, though it is with a more mathematical complexity. In particular, some well-known continuous and deterministic models are analytically and/or numerically discussed taking account of time value. In Section 2, we discuss an inventory system without backlogging allowed, and in Section 3, one with backlogging allowed is discussed. We examine the asymptotic characteristics of the total cost by perturbation of instantaneous interest rate. We further show numerical 
examples in Section 4 and describe how to determine the optimal inventory policies. We affirm that the concept of time value is useful to accurately evaluate the inventory management policies.

\section{AN INVENTORY SYSTEM WITHOUT BACKLOGGING ALLOWED}

In this section, we deal with the classical continuous and deterministic inventory management system without backlogging allowed. In order to focus on the results and simplify the exposition, we assume that the replenishment lead time can be ignored.

\section{Model and assumptions}

A single item is considered. The amount of item $Q$ is ordered when the stock level becomes 0 , and then goods are uniformly delivered with rate $S$ per unit time during time interval $t_{d}$. The demand is the rate $D$ per unit time, where $S>D$. Thus, during this interval $t_{d}$, the stock level increases with rate $S-D$ per unit time, which is the extra amount per unit time. After the amount is delivered, i.e. after time $t_{d}$, stocked goods are uniformly depleted, and again the stock level becomes 0 after time $t_{s}$. We define the interval that the stock level becomes 0 and again becomes 0 , i.e. from any ordering point to next one, as one cycle, whose length is $t_{0}=t_{d}+t_{s}$. The same cycle repeats itself again and again for an infinite time span. In this inventory system, the first order is made at time 0 , and the planning horizon is infinite. The costs considered are the following; a cost $K$ is associated with each order, and a holding cost $H$ per unit amount and per unit time is incurred for each inventory cycle, which may be interpreted as the annuity (e. g., see [2]).

Further, we introduce a continuous (an exponential) type interest rate $r(>0)$, where the present value of a unit of cost after a time interval $t$ is $\exp (-r t)$. The interest rate $r$ is constant for a given organization. For example, it could be the loan rate of the bank which has dealings with the company. In our model, $r$ indicates the compound interest rate. When we compare the economy using the interest rate as an index of the relative value in the industrial market, we may obtain $r$ directly by referring to the current market price of a Treasury bond at or about the same time as the operating time of the system.

Under these assumptions, we derive the total present value of cost for an infinite time span and obtain the optimum policy to minimize it (see fig. 1). 


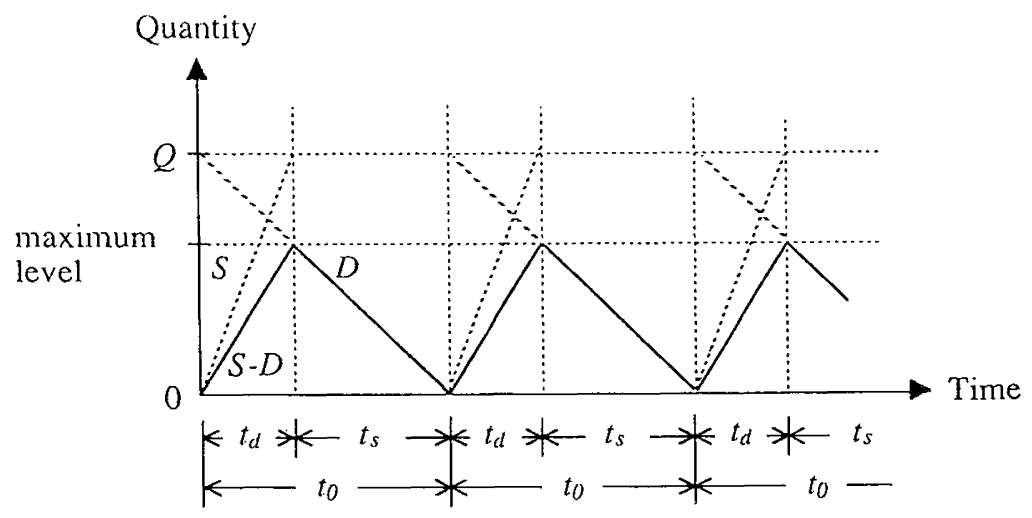

Figure 1. - State-diagram for one cycle (Case without backlogging allowed).

\section{Analysis and theorems}

We derive the total present value of cost for an infinite time span, $T C_{r}\left(t_{0}\right)$. The present value of inventory holding cost per one cycle is

$$
\begin{aligned}
H\left\{\int_{0}^{t_{d}}(S-D) t e^{-r t} d t+\int_{t_{d}}^{t_{0}} D\left(t_{0}-t\right) e^{-r t} d t\right\} \\
=\frac{H}{r^{2}}\left\{S\left(1-e^{-r(D / S) t_{0}}\right)-D\left(1-e^{-r t_{0}}\right)\right\} .
\end{aligned}
$$

Therefore, we have the total present value of cost per one cycle as follows:

$$
\varphi_{r}\left(t_{0}\right)=K+\frac{H}{r^{2}}\left\{\mathrm{~S}\left(1-e^{-r(D / S) t_{0}}\right)-D\left(1-e^{-r t_{0}}\right)\right\}
$$

Just after one cycle, the present value of a unit of cost is

$$
\delta_{r}\left(t_{0}\right)=e^{-r t_{0}}
$$

Then, when the system stars operating at time 0 , the total present value of cost for an infinite time span is

$$
\begin{aligned}
T C_{r}\left(t_{0}\right)=\sum_{n=0}^{\infty} \varphi_{r}\left(t_{0}\right) \delta_{r}\left(t_{0}\right)^{n} & =\frac{\varphi_{r}\left(t_{0}\right)}{1-\delta_{r}\left(t_{0}\right)} \\
& =\frac{K+\left(H / r^{2}\right)\left\{S\left(1-e^{-r(D / S) t_{0}}\right)-D\left(1-e^{-r t_{0}}\right)\right\}}{1-e^{-r t_{0}}} .
\end{aligned}
$$


We have

$$
\frac{d T C_{r}\left(t_{0}\right)}{d t_{0}}=\frac{e^{-r t_{0}}}{\left(1-e^{-r t_{0}}\right)^{2}} \xi\left(t_{0}\right)
$$

where

$$
\xi\left(t_{0}\right) \equiv \frac{H D}{r}\left(e^{r(1-(D / S)) t_{0}}-1\right)\left(1-e^{-r t_{0}}\right)-r \varphi_{r}\left(t_{0}\right) .
$$

Then, we have the following theorem.

THEOREM 1: In this system, there exists a finite and unique optimal ordering time interval $t_{0}^{*}\left(0<t_{0}^{*}<\infty\right)$, which minimizes the total present value of cost $T C_{r}\left(t_{0}\right)$, satisfying $\xi\left(t_{0}\right)=0$, and the corresponding optimal total present value of cost is

$$
T C_{r}\left(t_{0}^{*}\right)=\frac{H D}{r^{2}}\left\{e^{r(1-(D / S)) t_{0}^{*}}-1\right\}
$$

Proof: Differentiating $T C_{r}\left(t_{0}\right)$ with respect to $t_{0}$ and setting it equal to zero implies the equation $\xi\left(t_{0}\right)=0$. Further, with respect to $t_{0}$,

$$
\frac{d \xi\left(t_{0}\right)}{d t_{0}}=H D\left(1-\frac{D}{S}\right)\left(1-e^{-r t_{0}}\right) e^{t(1-(D / S)) t_{0}} .
$$

Since $\xi(0)<0, \xi(\infty)>0$, and $\xi\left(t_{0}\right)$ is strictly increasing and continuous, there exists a finite and unique $t_{0}^{*}\left(0<t_{0}^{*}<\infty\right)$ minimizing the total present value of cost $T C_{r}\left(t_{0}\right)$ as a finite and unique solution to $\xi\left(t_{0}\right)=0$. Substituting the relation of $\xi\left(t_{0}^{*}\right)=0$ into $T C_{r}\left(t_{0}^{*}\right)$ in equation (4) yields equation (7).

\section{Special cases}

We discuss the relationships between our results and earlier ones. In the first place, by perturbation of instantaneous interest rate, i.e. $r \rightarrow 0$, the total cost per unit time in the steady-state is obtained from equation (4) as follows:

$$
T C_{r s}\left(t_{0}\right) \equiv \lim _{r \rightarrow 0} r T C_{r}\left(t_{0}\right)=\frac{K+(H D / 2)(1-(D / S)) t_{0}^{2}}{t_{0}}
$$

Further, from equation (6), we obtain

$$
\lim _{r \rightarrow 0} \frac{1}{r} \xi\left(t_{0}\right)=\frac{H D}{2}\left(1-\frac{D}{S}\right) t_{0}^{2}-K .
$$


For the result mentioned above, the optimal ordering time interval which minimizes the total cost per unit time in the steady-state in equation (9) is

$$
t_{0 s}^{*}=\sqrt{\frac{2 K}{H D(1-D / S)}},
$$

and the corresponding total cost per unit time and the order quantity per one cycle in the steady-state become as follows respectively:

$$
\begin{aligned}
T C_{r s}\left(t_{0 s}^{*}\right) & =\sqrt{2 H D K(1-D / S)}, \\
Q_{s}^{*} & =\sqrt{\frac{2 D K}{H(1-D / S)}} .
\end{aligned}
$$

Especially, we can obtain the total cost per year, $A T C_{r s}\left(t_{0}\right)$ from equation (9):

$$
A T C_{r s}\left(t_{0}\right)=\frac{K D T}{Q_{a}}+\frac{Q_{a} H T}{2}\left(1-\frac{D}{S}\right),
$$

where $Q_{a}$ is the order quantity per one cycle, $T$ is the number of time units per one year, and clearly $D T$ is the demand rate per one year and $H T$ is the holding cost per one year. This annual cost obviously coincides with the classical result (e. g., see Hax and Candea [3], p. 136). In a later discussion, our results also include earlier classical ones in the similar fashions.

Secondly, let us consider the case in which the delivery rate per unit time is infinite, i.e. $S \rightarrow \infty$. Then, the total present value of cost for an infinite time span is obtained from equation (4) as follows:

$$
T C_{f}\left(t_{0}\right) \equiv \lim _{s \rightarrow \infty} T C_{r}\left(t_{0}\right)=\frac{K+\left(H D / r^{2}\right)\left(r t_{0}+e^{-r t_{0}}-1\right)}{1-e^{-r t_{0}}} .
$$

Further, from equation (6) we define

$$
p\left(t_{0}\right) \equiv \lim _{s \rightarrow \infty} \xi\left(t_{0}\right)
$$

and it may be realized immediately that

$$
p\left(t_{0}\right)=\frac{H D}{r}\left(e^{r t_{0}}-\frac{K r^{2}}{H D}-r t_{0}-1\right) .
$$

Therefore, from these results and Theorem 1 we can obtain the following theorem. 
THEOREM 2: There exists a finite and unique optimal ordering time interval $\tilde{t}_{0}\left(0<\tilde{\mathrm{t}}_{0}<\infty\right)$, which minimizes $T C_{f}\left(t_{0}\right)$, satisfying $p\left(t_{0}\right)=0$, and the optimal total present value of cost is

$$
T C_{f}\left(\tilde{t}_{0}\right)=\frac{H D}{r^{2}}\left(e^{r \tilde{t}_{0}}-1\right)
$$

Thirdly, we consider the case in which simultaneously $S \rightarrow \infty$ and $r \rightarrow 0$. From equation (15) the total cost per unit time in the steady-state is

$$
T C_{f s}\left(t_{0}\right) \equiv \lim _{r \rightarrow 0} r T C_{f}\left(t_{0}\right)=\frac{K+(H D / 2) t_{0}^{2}}{t_{0}} .
$$

Since from equation (17),

$$
\lim _{r \rightarrow 0} \frac{1}{r} p\left(t_{0}\right)=\frac{H D}{2} t_{0}^{2}-K
$$

the optimal ordering time interval which minimizes the total cost per unit time in the steady-state in equation (19) is given by

$$
\tilde{t}_{0 s}=\sqrt{\frac{2 K}{H D}} .
$$

Consequently, from Theorem 2 and equation (21), the optimal total cost per unit time and the ordering quantity per one cycle in steady-state are obtained as follows respectively:

$$
\begin{gathered}
T C_{f s}\left(\tilde{t}_{0 s}\right)=\lim _{r \rightarrow 0} r T C_{f}\left(\tilde{t}_{0}\right)=\sqrt{2 H D K}, \\
\widetilde{Q}_{s}=\sqrt{\frac{2 K D}{H}}
\end{gathered}
$$

\section{THE CASE WITH BACKLOGGING ALLOWED}

We consider an inventory system with backlogging allowed in contrast with Section 2. Notations in Section 2 are applied, unless otherwise stated.

\section{Model and assumptions}

A single item is considered. The quantity $Q$ is ordered when the shortage (backlogging, backorder) amount of stock becomes a prespecified one w, i.e. the stock level becomes $-w$, and then goods are uniformly delivered during time interval $t_{f}+t_{d}$. During this interval $t_{f}+t_{d}$, the stock level increases with rate $S-D$ per unit time, where the shortage is filled up during the first 
interval $t_{f}$ and the inventory increases during $t_{d}$. After $Q$ is delivered, i.e. after time $t_{f}+t_{d}$, stocked goods are uniformly demanded, the stock level becomes 0 after time $t_{s}$, and further after time $t_{r}$ the shortage amount becomes $w$ again, i.e. the stock level becomes $-w$ after time $t_{s}+t_{r}$. We define the interval that stock level becomes $-w$ and again it becomes $-w$, i.e. from any ordering point to next one, as one cycle, whose length is $t_{0}=t_{f}+t_{d}+t_{s}+t_{r}$. The cycle then repeats. In this inventory system, the first order is made at time 0 , and the planning horizon is infinite. Further, a cost $C$ per unit amount and per unit time is suffered for all shortages.

Under these assumptions, we derive the total present value of cost for an infinite time span and obtain the optimum policy to minimize it (see fig. 2).

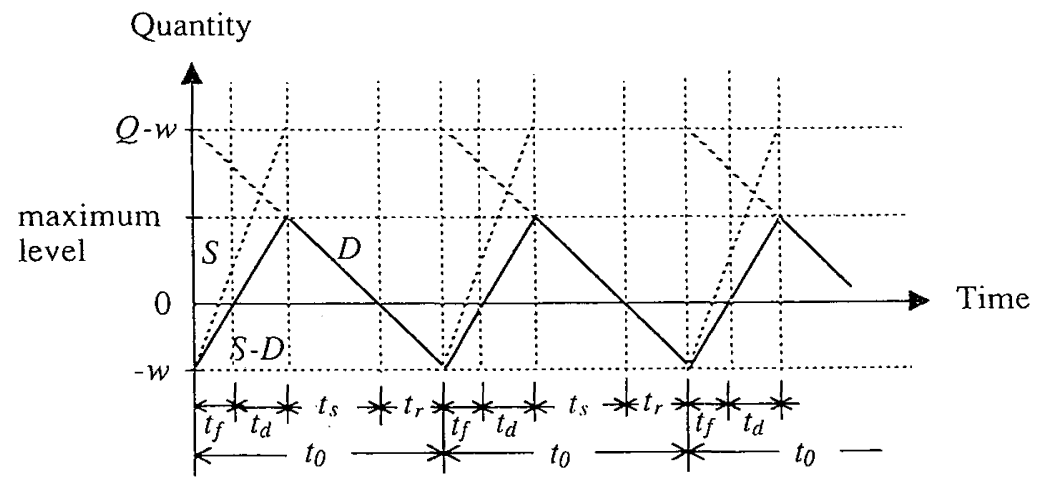

Figure 2. - State-diagram for one cycle (Case with backlogging allowed).

Analysis and other special cases

The total present value of cost per one cycle becomes

$$
\begin{aligned}
& \varphi_{R}\left(t_{0}, t_{r}\right)= K+\frac{H}{r^{2}}\left[-S e^{-r(D / s) t_{0}}+(S-D) e^{-r(D / S-D)) t_{r}}+D e^{-r\left(t_{0}-t_{r}\right)}\right] \\
&+C\left[\frac{1}{r^{2}}\left\{(S-D)\left(e^{-r(D / S-D)) t_{r}}-1\right)-D\left(e^{-r t_{0}}-e^{-r\left(t_{0}-t_{r}\right)}\right)\right\}\right. \\
&\left.+\frac{D}{r}\left(1-e^{-r t_{0}}\right) t_{r}\right] .
\end{aligned}
$$


Thus, when the system starts operating at time 0 , the total present value of cost for an infinite time span is obtained as follows:

$$
T C_{R}\left(t_{0}, t_{r}\right)=\sum_{n=0}^{\infty} \varphi_{R}\left(t_{0}, t_{r}\right) \delta_{R}\left(t_{0}, t_{r}\right)^{n}=\frac{\varphi_{R}\left(t_{0}, t_{r}\right)}{1-\delta_{R}\left(t_{0}, t_{r}\right)},
$$

where $\delta_{R}\left(t_{0}, t_{r}\right)$ is equivalent to $\delta_{r}\left(t_{0}\right)$ in equation (3), i.e.

$$
\delta_{R}\left(t_{0}, t_{r}\right)=e^{-r t_{0}} .
$$

We must obtain the optimal policies minimizing the total present value $T C_{R}\left(t_{0}, t_{r}\right)$ in equation (25). However, it is analytically difficult to derive a pair of the optimal time intervals $\left(t_{0}^{*}, t_{r}^{*}\right)$, which minimize $T C_{R}\left(t_{0}, t_{r}\right)$. Therefore we must seek $\left(t_{0}^{*}, t_{r}^{*}\right)$ and $T C_{R}\left(t_{0}^{*}, t_{r}^{*}\right)$ numerically. In Section 4 , we show the numerical examples for this criterion.

Let us discuss properties of the criterion introduced in equation (25) next. From equation (25), the total cost per unit time in the steady-state is given by

$$
\begin{array}{rl}
T C_{R S}\left(t_{0}, t_{r}\right) \equiv \lim _{r \rightarrow 0} r & T C_{R}\left(t_{0}, t_{r}\right) \\
& K+((H+C) / 2)\left[\left(D^{2} /(S-D)\right) t_{r}^{2}+D\left(t_{0}-t_{r}\right)^{2}\right] \\
= & \frac{-(D / 2) t_{0}^{2}((D / S) H+C)+D C t_{0} t_{r}}{t_{0}}
\end{array}
$$

or alternatively using $Q$ and $w$,

$$
T C_{R S}\left(t_{0}, t_{r}\right)=\frac{K D}{Q}+\frac{H Q}{2}\left(1-\frac{D}{S}\right)-H w+\frac{(H+C) w^{2}}{2 Q(1-(D / S))} .
$$

On the other hand, when $S \rightarrow \infty$, the total present value of cost for an infinite time span becomes from equation (25)

$$
\begin{aligned}
& T C_{F}\left(t_{0}, t_{r}\right) \equiv \lim _{S \rightarrow \infty} T C_{R}\left(t_{0}, t_{r}\right) \\
& =\frac{\left\{\begin{array}{c}
K+\left(H D / r^{2}\right)\left[r\left(t_{0}-t_{r}\right)-1+e^{-r\left(t_{0}-t_{r}\right)}\right] \\
+C D\left[\left(1 / r^{2}\right)\left(-r t_{r}-e^{-r t_{0}}+e^{-r\left(t_{0}-t_{r}\right)}\right)+(1 / r)\left(1-e^{-r t_{0}}\right) t_{r}\right]
\end{array}\right\}}{1-e^{-r t_{0}}} .
\end{aligned}
$$


Further, when simultaneously $S \rightarrow \infty$ and $r \rightarrow 0$, the total cost per unit time in the steady-state is from equation (29)

$$
\begin{aligned}
T C_{F S}\left(t_{0}, t_{r}\right) \equiv \lim _{r \rightarrow 0} r T C_{F}\left(t_{0}, t_{r}\right) \\
=\frac{K+((H+C) D / 2)\left(t_{0} t_{r}\right)^{2}-(C D / 2) t_{0}^{2}+C D t_{0} t_{r}}{t_{0}},
\end{aligned}
$$

or alternatively using $Q$ and $w$,

$$
T C_{F S}\left(t_{0}, t_{r}\right)=\frac{K D}{Q}+\frac{H Q}{2}-H w+\frac{(H+C) w^{2}}{2 Q} .
$$

Consequently, the optimal ordering quantity and shortage amount of stock per one cycle and the corresponding total cost per unit time in steady-state are obtained as follows respectively:

$$
\begin{gathered}
Q_{S}^{*}=\sqrt{\frac{2 K D(H+C)}{H C},} \\
w_{S}^{*}=\sqrt{\frac{2 K D H}{C(H+C)}}, \\
\min _{Q, \omega} T C_{F S}\left(t_{0}, t_{r}\right)=\sqrt{\frac{2 K D H C}{H+C}} .
\end{gathered}
$$

\section{NUMERICAL EXAMPLES}

Using the results in Sections 2 and 3, we show the numerical examples with time value. We use Mathematica as a tool of numerical calculation, which is a system in order to execute mathematics using computer developed by Wolfram [7].

\section{Case 1 (system without backlogging allowed)}

We apply the inventory system without backlogging allowed when the instantaneous interest rate $r$ changes from 0.10 to 0.20 . The optimal ordering time intervals $t_{0}^{*}$ and the corresponding total present values of cost for an infinite time span $T C_{r}\left(t_{0}^{*}\right)$ are shown in Table I. Newton Raphson method is applied to solve $\xi\left(t_{0}\right)=0$ numerically. We can realize that $T C_{r}\left(t_{0}^{*}\right)$ decreases and $t_{0}^{*}$ increases as $r$ increases. This result is reasonable. In particular, it should be noted that $t_{0}^{*}$ is insensitive relatively to changes in $r$. Further, when $r$ is $0.05,0.10,0.15$, and 0.20 , the behavior of the total present value of 
TABLE I

Case without backlogging allowed: Dependence of $r$ in $t_{0}^{*}$ and its associated $T C_{r}\left(t_{0}^{*}\right)$ $(S=4$ [units], $D=3$ [units], $K=36.5$ [dollars], $H=60.5$ [dollars]).

\begin{tabular}{|c|c|c|c|c|c|c|}
\hline$r$ & 0.10 & 0.11 & 0.12 & 0.13 & 0.14 & 0.15 \\
$t_{0}^{*}$ & 1.287 & 1.289 & 1.290 & 1.291 & 1.293 & 1.294 \\
$T C_{r}\left(t_{0}^{*}\right)$ & $5.886 \times 10^{5}$ & $5.368 \times 10^{5}$ & $4.932 \times 10^{5}$ & $4.564 \times 10^{5}$ & $4.252 \times 10^{5}$ & $3.973 \times 10^{5}$ \\
\hline$r$ & 0.16 & 0.17 & 0.18 & 0.19 & 0.20 & \\
$t_{0}^{*}$ & 1.295 & 1.297 & 1.298 & 1.299 & 1.301 & \\
$T C_{r}\left(t_{0}^{*}\right)$ & $3.738 \times 10^{5}$ & $3.530 \times 10^{5}$ & $3.342 \times 10^{5}$ & $3.173 \times 10^{5}$ & $3.025 \times 10^{5}$ & \\
\hline
\end{tabular}

cost $T C_{r}\left(t_{0}\right)$ for the ordering time interval $t_{0}$ is shown in figure 3 respectively. There exists a unique minimum value certainly.

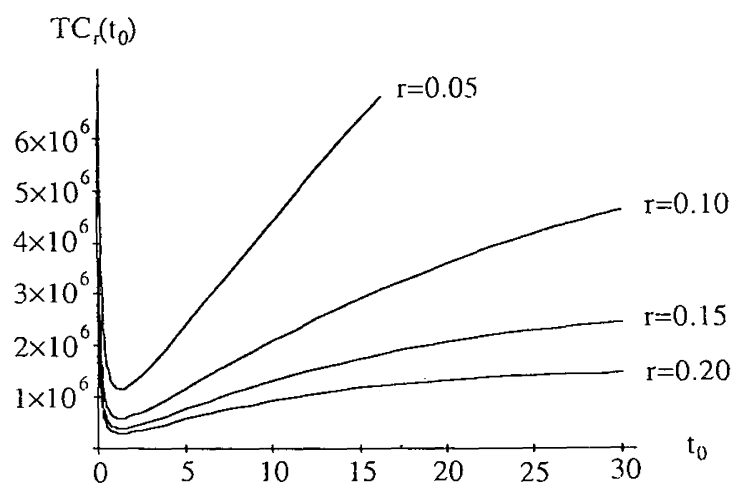

Figure 3. - Behavior of $T C_{r}\left(t_{0}\right)$ for $t_{0}(S=4$ [units], $D=3$ [units], $K=36.5$ [dollars], $H=60.5$ [dollars]).

Case 2 (system with backlogging allowed)

We consider the system with backlogging allowed. When $r$ changes from 0.10 to 0.20 , using the FindMinimum function of Mathematica pairs of $\left(t_{0}^{*}, t_{r}^{*}\right)$ and the corresponding $T C_{R}\left(t_{0}^{*}, t_{r}^{*}\right)$ are shown in Table II. In contrast with Case 1 , we can realize that a pair of $\left(t_{0}^{*}, t_{r}^{*}\right)$ decrease by contraries as $r$ increases. This result is very interesting. Thus, the present value gives a contrary tendency, and $t_{0}^{*}$ is more sensitive to $r$ than the case without backlogging allowed. A three-dimensional diagram of $t_{0}, t_{r}$ and $T C_{R}\left(t_{0}, t_{r}\right)$ is shown in figure 4 . It is shown from the diagram that the strong dependence of $\left(t_{0}, t_{r}\right)$ in $T C_{R}\left(t_{0}, t_{r}\right)$ exists.

We further consider the case with fixed $t_{r}$. In practical inventory management, time interval $t_{r}$ that exists for shortage allowed is often set in advance. Behavior of the total present value of cost $T C_{R}\left(t_{0}, t_{r}\right)$ for $t_{0}$ is shown in 
TABLE II

Case with backlogging allowed: Dependence of $r$ in $\left(t_{0}^{*}, t_{r}^{*}\right)$ and their associated $T C_{R}\left(t_{0}^{*}, t_{r}^{*}\right)$ ( $S=4$ [units], $D=3$ [units], $K=36.5$ [dollars], $H=60.5$ [dollars], $C=500$ [dollars]).

\begin{tabular}{|c|c|c|c|c|c|c|}
\hline$r$ & 0.10 & 0.11 & 0.12 & 0.13 & 0.14 & 0.15 \\
$t_{0}^{*}$ & 11.870 & 11.657 & 11.450 & 11.248 & 11.053 & 10.864 \\
$t_{r}^{*}$ & 2.933 & 2.879 & 2.827 & 2.776 & 2.726 & 2.679 \\
$T C_{R}\left(t_{0}^{*}, t_{r}^{*}\right)$ & $7.712 \times 10^{4}$ & $7.267 \times 10^{4}$ & $6.899 \times 10^{4}$ & $6.591 \times 10^{4}$ & $6.329 \times 10^{4}$ & $6.105 \times 10^{4}$ \\
\hline$r$ & 0.16 & 0.17 & 0.18 & 0.19 & 0.20 & \\
$t_{0}^{*}$ & 10.681 & 10.504 & 10.332 & 10.167 & 10.007 & \\
$t_{r}^{*}$ & 2.632 & 2.588 & 2.544 & 2.502 & 2.462 & \\
$T C_{R}\left(t_{0}^{*}, t_{r}^{*}\right)$ & $5.910 \times 10^{4}$ & $5.740 \times 10^{4}$ & $5.590 \times 10^{4}$ & $5.457 \times 10^{4}$ & $5.339 \times 10^{4}$ & \\
\cline { 2 - 6 }
\end{tabular}

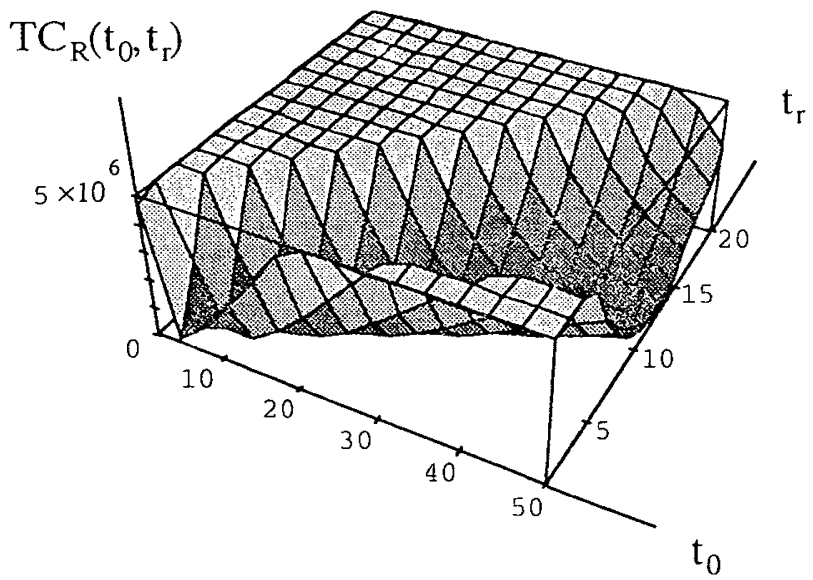

Figure 4. - Three-dimensional diagram of $t_{0}, t_{r}$ and $T C_{R}\left(t_{0}, t_{r}\right)$ ( $S=4$ [units], $D=3$ [units], $K=36.5$ [dollars], $H=60.5$ [dollars], $C=500$ [dollars], $r=0.1$ ).

figures 5 and 6 when $r$ changes from 0.05 to 0.20 and $t_{r}$ changes from 2 to 8 , respectively. Certainly we can find the existence of the minimum value, respectively.

\section{CONCLUDING REMARKS}

In this tutorial paper, we have discussed two typical continuous demand inventory models considering time value. One is the model without backlogging allowed, and the other is with backlogging allowed. We have shown that the instantaneous interest rate or the time value has a great effect and is important and inclusive for the cost criterion in the inventory management 


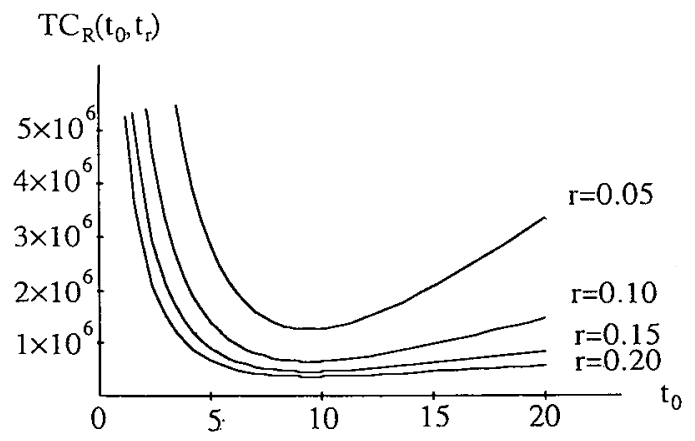

Figure 5. - Behavior of $T C_{R}\left(t_{0}, t_{r}\right)$ for $t_{0}$ and fixed $t_{r}(S=4$ [units], $D=3$ [units], $K=36.5$ [dollars], $H=60.5$ [dollars], $C=500$ [dollars], $t_{r}=4.0$ ).

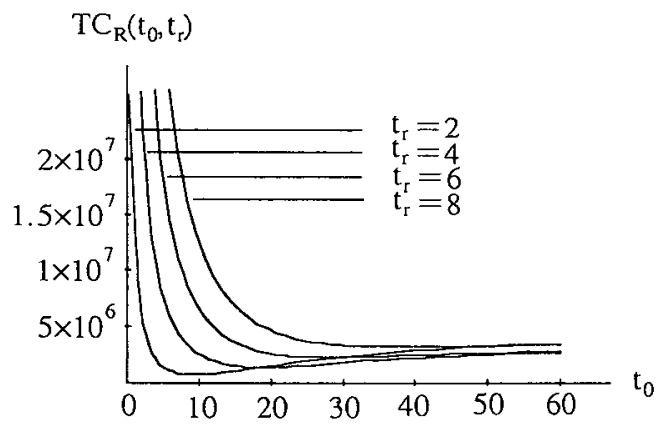

Figure 6. - Behavior of $T C_{R}\left(t_{0}, t_{r}\right)$ for $t_{0}$ and fixed $t_{r}$ ( $S=4$ [units], $D=3$ [units], $K=36.5$ [dollars], $H=60.5$ [dollars], $C=500$ [dollars], $r=0.1$ ).

system. Although we have used the typical and simple models to place great emphasis on time value, this concept can be applied to a discrete or a stochastic inventory problem. Further, we can deal with the case that the interest rate obeys any probability distribution, by applying this concept.

\section{ACKNOWLEDGEMENTS}

The authors would like to thank the referee of this journal for pointing out the references [2], [6], and improving the paper. This work was supported in part by the Research Program under the Institute for Advanced Studies of the Hiroshima Shudo University, Hiroshima 73131, Japan. 


\section{REFERENCES}

1. E. S. Buffa and R. K. SARin, Modern Production/Operations Management, Eighth Edition, John Wiley \& Sons, 1987.

2. C. Gurnani, Economic Analysis of Inventory Systems, Internat. Production Res., 1983, 21, pp. 261-277.

3. A. C. Hax and D. Candea, Production and Inventory Management, Prentice-Hall, Englewood Cliffs, 1984.

4. R. J. Tersine, Principles of Inventory and Materials Management, Third Revised Edition, North Holland, 1988.

5. H. E. Thомpson, Inventory Management and Capital Budgeting: A Pedagogical Note, Decision Sciences, 1975, 6, pp. 383-398.

6. R. R. TRIPPI and D. E. Lewin, A present Value Formulation of the Classical EOQ Problem, Decision Sciences, 1974, 5, pp. 30-35.

7. S. Wolfram, Mathematica: A System for Doing Mathematics by Computer, Addison-Wesley, 1988. 